RACIC 6(2) (2021)
UNIVERSITAS
ABDURRAB
http://jurnal.univrab.ac.id/index.php/racic

\title{
PENGARUH PENGGUNAAN ASBUTON BUTIR T.5/50 UNTUK PERKERASAN ASPAL SMA (STONE MATRIX ASPHALT)
}

\author{
Novia Anggraini, Winayati, dan Hendri Rahmat \\ Program Studi Teknik Sipil, Fakultas Teknik, Universitas Lancang Kuning \\ Jl. Yos Sudarso KM. 8 Rumbai, Pekanbaru, Riau \\ (0761) 52248
}

Noviaangraini20@gmail.com

\section{Info Artikel}

Sejarah Artikel:

Diterima : September 2021

Disetujui : Desember 2021

Dipublikasikan : Des 2021

Keywords:

Asbuton, filler, Marshall, Stone matrix asphalt
Jalan raya sebagai salah satu sarana transportasi darat, kegunaannya dirasakan semakin penting untuk menunjang peningkatan perekonomian nasional. Salah satu solusi untuk membangun jalan ini adalah dengan mencoba penggunaan perkerasan aspal SMA (Stone Matrix Asphalt). Stone Matrix Asphalt (SMA) adalah beton aspal dengan campuran panas terdiri dari agregat kasar, agregat halus, bahan pengisi serta bahan pengikat (aspal). Tujuan penelitian untuk mengetahui pengaruh penggunaan Asbuton butir T.5/20 untuk perkerasan aspal Stone Matrix Asphalt terhadap karakteristik Marshall. Material yang digunakan pada campuran yaitu agregat kasar yang berasal dari pangkalan, agregat halus, aspal pen 60/70 serta asbuton butir T.5/20 yang berasal dari Pulau Buton Sulawesi Tenggara. Pengujian Marshall untuk aspal Stone Matrix Asphalt pada campuran agregat dengan kadar aspal 4,5\%, 5\%, $5,5 \%$ dan $6 \%$ diperoleh nilai kadar aspal optimum sebesar 5,75\%. Setelah didapatkan kadar aspal optimum dilakukan modifikasi dengan penambahan asbuton butir T.5/20 pada campuran agregat sebanyak $2 \%, 2,5 \%$, dan 3\%. Semakin banyak penggunaan asbuton butir pada campuran maka nilai stabilitas yang didapatkan semakin meningkat nilai nya. Stabilitas merupakan indikator kekuatan lapis perkerasan dalam memikul beban lalu-lintas. Aspal Stone Matrix Asphalt didesain untuk mendapatkan kadar rongga yang besar, sedangkan persentase rongga VMA yang didapatkan nilainya semakin kecil dan tidak memenuhi syarat spesifikasi.

Kata Kunci: asbuton, filler, marshall, stone matrix asphalt

\section{Abstract}

The highway as one of the means of land transportation, its usefulness is felt to be increasingly important to increase the improvement of the national economy. One solution to build this road is to try the use of SMA (Stone Matrix Asphalt) asphalt pavement. Stone Matrix Asphalt (SMA) is asphalt concrete with a hot mix consisting of coarse aggregate, fine aggregate, filler material and binder (asphalt). The purpose of the study was to determine the effect of using Asbuton grain T.5/20 for asphalt pavement of the Asphalt Stone Matrix on Marshall characteristics. The materials used in the mixture are coarse aggregate from the base, fine aggregate, 
asphalt pen 60/70 and asbuton grain T.5/20 originating from Buton Island, Southeast Sulawesi. Marshall test for asphalt matrix asphalt on aggregate mixture with asphalt content of $4.5 \%, 5 \%, 5.5 \%$ and $6 \%$ obtained the optimum asphalt content value of $5.75 \%$. After obtaining the optimum asphalt content, modifications were made by adding asbuton grain T.5/20 to the aggregate mixture as much as $2 \%, 2.5 \%$, and $3 \%$. The more use as a grain in the mixture, the higher the value obtained. Stability is an indicator of pavement strength under traffic loads. Asphalt Stone Matrix which is designed to obtain a large void content, while the proportion of VMA cavities obtained is getting smaller and does not meet the specification requirements.

Kata Kunci: asbuton, filler, marshall, stone matrix asphalt

\begin{tabular}{lr} 
& \\
\cline { 2 - 3 } & Universitas Abdurrab \\
\hline Alamat korespondensi: & ISSN 2527-7073 \\
J1. Yos Sudarso KM. 8 Rumbai, Pekanbaru, Riau & \\
E-mail: Noviaangraini20@gmail.com &
\end{tabular}

\section{PENDAHULUAN}

Stone Matrix Asphalt (SMA) adalah beton aspal dengan campuran panas yang terdiri dari agregat kasar, agregat halus, bahan pengisi dan bahan pengikat (aspal). Pada lapis perkerasan lentur, SMA digunakan sebagai lapis permukaan perkerasan jalan dengan susunan agregat yang bergradasi terbuka (open graded) atau biasa juga disebut dengan gradasi seragam yang artinya kandungan agregat halusnya sedikit sehingga terdapat lebih banyak rongga-rongga atau ruang antar agregat yang kosong. Pada lapisan permukaan terdapat lapis, lapis antara dan lapis pondasi dimana Stone Matrix Asphalt sebagai lapis aus terletak diatas lapis antara. Salah satu teknologi pengerasan jalan adalah teknologi Stone Matrix Asphalt (SMA), yaitu jenis perkerasan dengan gradasi terbuka (open graded) yang terdiri dari: agregat kasar (spilt) dengan jumlah fraksi tinggi, campuran agregat halus, bahan pengisi (filler) dan aspal dengan kadar relatif tinggi. Pada campuran SMA terdapat berbagai bahan penyusun yang proporsinya dapat divariasi seperti proporsi aspal ataupun proporsi filler. (Timbonga, C. F,Dkk, 2021).

Aspal buton merupakan salah satu aspal alam yang hanya terdapat di pulau Buton, Sulawesi Tenggara, Indonesia. Salah satu hasil pengolahan dari aspal Buton yang saat ini banyak digunakan untuk lapis perkerasan adalah BGA (Buton Granular Asphalt). Asbuton butir T.5/20 memiliki fungsi untuk memodifikasi aspal dan campuran sehingga memiliki kinerja yang lebih baik dan merupakan type filler yang memiliki manfaat lebih baik dari filler type lain. Penelitian ini bermaksud kadar asbuton optimum sebagai filler pada campuran Stone Matrix Asphalt (SMA) (Ramdhani, F., dkk, 2015).

Penelitian ini bermaksud menambahkan asbuton butir T. 5/20 pada campuran Stone Matrix Asphalt (SMA) dan melihat seberapa besar pengaruhnya, apakah pengaruh yang didapat lebih kuat. Untuk mengetahui hal tersebut diperlukan pengujian Marshall test dilaboratorium. 


\section{TINJAUAN PUSTAKA}

\section{Lokasi Penelitian}

Penelitian ini dilokasikan di Laboratorium PT. RMB (Riau Mas Bersaudara) di Jl. PekanbaruBangkinang KM. 24 Desa Rimbo Panjang.

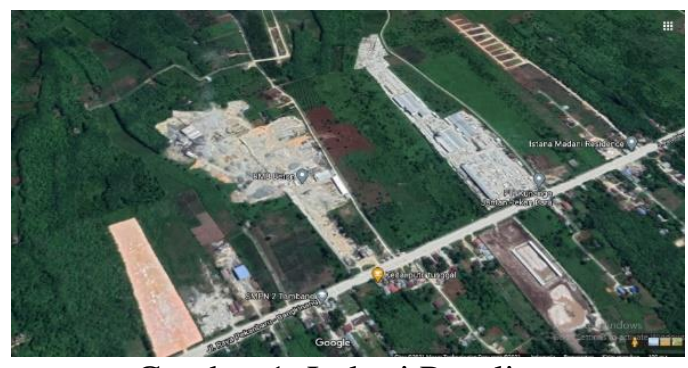

Gambar 1. Lokasi Penelitan

\section{Bahan}

Adapun bahan yang digunakan dalam penelitian ini yaitu :

1. Agregat kasar yang digunakan berasal dari PT. Riau Mas Bersaudara, Rimbo Panjang, Kab. Kampar.

2. Agregat halus yang digunakan berasal dari PT. Riau Mas Bersaudara, Rimbo Panjang, Kab. Kampar.

3. Aspal yang digunakan pada penelitian ini adalah aspal keras produksi Pertamina Rebana penetrasi $60 / 70$.

4. Filler atau material lolos saringan No. 8 yang digunakan dalam penelitian ini adalah Asbuton Butir T.5/20 Berasal Dari Sulawesi, Pulau Buton.

\section{Alat yang Digunakan}

Alat yang digunakan dalam penelitian ini adalah :

1. Peralatan dan jenis untuk agregat dan aspal

Peralatan yang digunakan sebagai berikut :
a. Alat pembagi
b. Alat saringan lengkap
c. Alat untuk menguji berat jenis semu dan berat jenis bulk
d. Alat pemeriksaan keausan dengan mesin abrasi
e. Alat untuk pemeriksaan gumpalan lempung dan butiran yang mudah pecah
f. Alat untuk pengujian partikel ringan dalam agregat.

2. Peralatan untuk pengujian campuran beraspal

Peralatan yang harus dipersiapkan sebagai berikut :
a. Alat pembuat briket
b. Satu unit alat pengujian marshall
c. Alat pengeluar briket hasil pemadatan
d. Bak pemanas air
e. Oven dengan pengatur temperatur
f. Alat uji berat jenis campuran maksimum lengkap

\section{Tahapan Penelitian}

Tahapan penelitian dalam penelitian ini adalah : 
1. Dilakukan penimbangan agregat sesuai dengan presentase pada target gradasi yang diinginkan untuk masing-masing fraksi dengan berat campuran kira-kira 1200 gram untuk diameter 4 inchi, kemudian dilakukan pengeringan campuran agregat tersebut sampai beratnya tetap sampai suhu $(155 \pm 1)^{\circ} \mathrm{c}$.

2. Dilakukan pemanasan aspal untuk pencampuran pada $(100 \pm 10)^{\circ} \mathrm{C}$ untuk aspal tetap mencair. temperatur campuran agregat dan aspal tetap maka pencampuran dilakukan di atas pemanas dan diaduk hingga rata mencapai suhu yang ditetapkan yaitu $(155 \pm 1)^{\circ} \mathrm{C}$ setelah di lakukan pemanasaan campur Asbuton butir 30 gram.

3. Setelah temperatur pemadatan tercapai yaitu pada $(155 \pm 1)^{\circ} \mathrm{c}$, maka campuran tersebut dimasukkan ke dalam cetakan yang telah dipanasi pada temperatur $100^{\circ}$ dan diolesi vaselin terlebih dahulu, serta bagian bawah cetakan diberi sepotong kertas filter atau kertas (paper) yang telah dipotong sesuai dengan diameter cetakan sambil ditusuk-tusuk dengan spatula sebanyak 15 kali di bagian tepi dan 10 kali di bagian tengah.

4. Pemadatan standar dilakukan dengan pemadat manual dengan jumlah tumbukan 50 kali di bagian sisi atas kemudian dibalik dan sisi bagian bawah juga ditumbuk sebanyak 50 kali dengan variasi $4.5 \%$ - $6.0 \%$ dan K.A.O + Filler 2.0\%, 2,5\% dan 3.0\%.

5. Setelah proses pemadatan selesai benda uji didiamkan agar suhunya turun, setelah dingin benda uji dikeluarkan dengan ejektor dan diberi kode.

6. Benda uji dibersihkan dari kotoran yang menempel dan diukur tinggi benda uji dengan ketelitian 0,1 $\mathrm{mm}$ dan ditimbang beratnya di udara.

7. Benda uji direndam dalam air selama 10-24 jam supaya jenuh.

8. Setelah jenuh benda uji ditimbang dalam air.

9. Benda uji dikeluarkan dari bak dan dikeringkan dengan kain pada permukaan agar kondisi kering permukaan jenuh (saturated surface dry, SSD) kemudian ditimbang.

10. Benda uji direndam dalam bak perendaman pada suhu $60 \pm 1^{\circ} \mathrm{C}$ selama 30 hingga 40 menit. Untuk uji perendaman mendapatkan stabilitas sisa pada suhu $60 \pm 1^{\circ} \mathrm{C}$ selama 24 jam.

11. Bagian dalam permukaan kepala penekan dibersihkan dan dilumasi agar benda uji mudah dilepaskan setelah pengujian.

12. Benda uji dikeluarkan dari bak perendam, lalu diletakkan tepat di tengah pada bagian bawah kepala penekan kemudian bagian atas kepala diletakkan dengan memasukkan lewat batang penuntun. Setelah pemasangan sudah lengkap maka diletakkan tepat di tengah alat pembebanan. Kemudian arloji kelelehan (flow meter) dipasang pada dudukan di atas salah satu batang penuntun.

13. Kepala penekan dinaikkan hingga menyentuh atas cincin penguji, kemudian diatur kedudukan jarum arloji penekan dan arloji kelelehan pada angka nol.

14. Pembebanan dilakukan dengan kecepatan tetap $51 \mathrm{~mm}$ (2 inch) per menit, hingga kegagalan benda uji terjadi yaitu pada saat arloji pembebanan berhenti dan mulai kembali berputar menurun, pada saat itu pula dibuka arloji kelelehan. Titik pembacaan pada saat benda uji mengalami kegagalan adalah merupakan nilai stabilitas Marshall.

15. Setelah pengujian selesai, kepala penekan diambil, bagian atas dibuka dan benda uji dikeluarkan. Waktu yang diperlukan dari saat diangkatnya benda uji dari rendaman air sampai tercapainya beban maksimum tidak boleh melebihi 60 detik.

16. Setelah Pengujian Selesai, di buat analisa data marshall sesuai standart Pengujian Bina Marga Spesifikasi 2018.

\section{METODE}

Dari data-data di atas dapat dihitung nilai VMA (Void in Mineral Aggregate), VFA (Void Filled With Asphalt), VIM (Void in Total Mix), stabilitas (stability), MQ (Marshall Quetient), kelelehan (Flow),dan kepadatan (Density) dapat dihitung berdasarkan data-data berikut :

1. Berat Jenis Aspal $=($ Berat $/$ Volume $)$

2. Berat Jenis Agregat 
Dapat dihitung sebagai berikut :

a. Berat jenis bulk agregat

$\mathrm{Gsb}=\frac{\mathrm{P} 1+\mathrm{P} 2+\ldots \ldots \ldots \ldots . \mathrm{Pn}}{\frac{\mathrm{P} 1}{\mathrm{G} 2}+\frac{\mathrm{P} 2}{\mathrm{G} 2}+\ldots \ldots \ldots \ldots+\frac{\mathrm{Pn}}{\mathrm{Gn}}}$.

Keterangan:

$\mathrm{Gsb} \quad=$ Berat jenis bulk total agregat

$\mathrm{P} 1, \mathrm{P} 2 \mathrm{n}=$ Persentase masing-masing fraksi agregat

G1, G2 n = Berat jenis bulk masing-masing fraksi agregat

b. Berat jenis efektif agregat

$\mathrm{Gse}=\frac{\mathrm{Pmm}-\mathrm{Pb}}{\frac{\mathrm{Pmm}}{\mathrm{Gmm}}-\frac{\mathrm{Pb}}{\mathrm{Gb}}}$

Keterangan:

Gse = Berat jenis efektif agregat

Pmm = Persentase berat total campuran $(=100)$

$\mathrm{Gmm} \quad=$ Berat jenis maksimum campuran, rongga udara $0(\mathrm{Nol})$

$\mathrm{Pb} \quad$ = Kadar aspal berdasarkan berat jenis maksimum

$\mathrm{Gb} \quad=$ Berat jenis aspal

c. Berat jenis maksimum campuran

$\mathrm{Gmm}=\frac{\mathrm{Pmm}}{\frac{\mathrm{Ps}}{\mathrm{Gse}}+\frac{\mathrm{Pb}}{\mathrm{Gb}}}$

Keterangan:

$\mathrm{Gmm}=$ Berat jenis maksimum campuran, rongga udara 0 (Nol)

Pmm = Persentase berat total campuran $(=100)$

$\mathrm{Pb}=$ Kadar aspal berdasarkan berat jenis maksimum.

Ps = Kadar agregat persen terhadap berat total campuran.

Gse $\quad=$ Berat jenis efektif agregat.

$\mathrm{Gb} \quad=$ Berat jenis aspal

3. Penyerapan Aspal

$\mathrm{Pba}=100 \times \frac{\text { Gse-Gsb }}{\text { Gse } \times \mathrm{Gsb}} \times \mathrm{Gb}$

Keterangan:

$\mathrm{Pba} \quad=$ Penyerapan aspal, persen total agregat

$\mathrm{Gsb} \quad=$ Berat jenis bulk agregat

Gse $\quad=$ Berat jenis efektif agregat

$\mathrm{Gb} \quad=$ Berat jenis aspal

4. Kadar Aspal Efektif

$\mathrm{Pbe}=\mathrm{Pb} \times \frac{\mathrm{Pba}}{100} \times \mathrm{Ps}$

Keterangan:

$\mathrm{Pbe} \quad=$ Kadar aspal efektif, persen total agregat

$\mathrm{Pb} \quad$ = Kadar aspal persen terhadap berat total campuran

$\mathrm{Pba} \quad=$ Penyerapan aspal, persen total agregat

Ps = Kadar agregat, persen terhadap berat total campuran

5. Rongga diantara Mineral Agregat (VMA)

VMA dapat dihitung pula terhadap berat campuran total atau terhadap berat agregat total.

Perhitungan VMA terhadap campuran total dengan persamaan: 


$$
V M A=100 \times \frac{G m b \times P s}{G s b} .
$$

Keterangan:
$V M A$
= Rongga diantara mineral agregat, persen volume bulk
Gsb
$=$ Berat jenis bulk agregat
Gmb
$=$ Berat jenis bulk campuran padat
Ps
$=$ Kadar agregat, persen terhadap berat total campuran

\section{HASIL DAN PEMBAHASAN}

\section{Hasil Pengujian Karakteristik Aspal}

Pengujian sifat aspal produksi pertamina dengan penetrasi 60/70 yang dilakukan di laboratorium PT.RMB dapat ditunjukkan pada tabel 1.

Tabel 1. Hasil pengujian karakteristik aspal pada SMA (stone matrix asphalt)

\begin{tabular}{ccccc}
\hline No. & Jenis Pengujian & Metode & Persyaratan & $\begin{array}{c}\text { Hasil } \\
\text { Pengujian }\end{array}$ \\
\hline 1. & $\begin{array}{c}\text { Penetrasi,25 }{ }^{\prime} \mathrm{C} ; 100 \text { gr; } 5 \\
\text { detik; 0,1 mm }\end{array}$ & SNI 2456:2011 & $60-70$ & $61.6 \mathrm{~mm}$ \\
\hline 2. & Titik Lembek. 'C & SNI 2434:2011 & $\geq 48$ & $49.0^{\circ} \mathrm{c}$ \\
\hline 3. & Dektalitas 25'C, cm & SNI 2432:2011 & $\geq 100$ & $140 \mathrm{~cm}$ \\
\hline 4. & Berat Jenis & SNI 2441:2011 & $\geq 1.0$ & 1.035 \\
\hline 5. & Viskositas Kinemetis & ASTM D2170-10 & $\geq 300$ & $355 \%$ \\
\hline
\end{tabular}

\section{Hasil Pengujian Karakteristik Agregat Kasar}

Pemeriksaan ini dimaksudkan untuk menentukan berat jenis agregat kasar terhadap penyerapan air. Hasil dari pengujian agregat kasar dilaboratorium dapat dilihat pada tabel 2.

Tabel 2. Hasil pengujian karakteristik agregat kasar pada SMA (stone matrix asphalt)

\begin{tabular}{|c|c|c|c|c|c|}
\hline \multicolumn{3}{|c|}{ Pengujian } & Metode & Nilai & Hasil \\
\hline \multicolumn{2}{|c|}{$\begin{array}{l}\text { Kekekalan Bentuk } \\
\text { Terhadap Larutan }\end{array}$} & $\begin{array}{l}\text { Natrium } \\
\text { sulfat }\end{array}$ & \multirow[t]{2}{*}{$\begin{array}{l}\text { SNI } 3407: \\
2008\end{array}$} & Maks. 12 & $2.5 \%$ \\
\hline & & $\begin{array}{l}\text { Magnesium } \\
\text { sulfat }\end{array}$ & & $\begin{array}{c}\text { Maks. } 18 \\
\%\end{array}$ & $7.0 \%$ \\
\hline \multirow{4}{*}{$\begin{array}{c}\text { Abrasi } \\
\text { dengan } \\
\text { mesin } \\
\text { Los } \\
\text { Angeles }\end{array}$} & \multirow{2}{*}{$\begin{array}{l}\text { Campuran } \\
\text { AC } \\
\text { Modifikasi } \\
\text { dan SMA }\end{array}$} & 100 putaran & \multirow{4}{*}{$\begin{array}{c}\text { SNI } \\
2417: 2008\end{array}$} & Maks. 6\% & $5.3 \%$ \\
\hline & & 500 putaran & & $\begin{array}{l}\text { Maks. } \\
30 \%\end{array}$ & $21.2 \%$ \\
\hline & \multirow{2}{*}{$\begin{array}{l}\text { Semua jenis } \\
\text { campuran } \\
\text { beraspal } \\
\text { bergradasi } \\
\text { lainya }\end{array}$} & 100 putaran & & Maks. $8 \%$ & - \\
\hline & & 500 putaran & & $\begin{array}{l}\text { Maks. } \\
40 \%\end{array}$ & - \\
\hline \multicolumn{3}{|c|}{ Kelekatan agregat terhadap aspal } & SNI & Min. $95 \%$ & $100 \%$ \\
\hline
\end{tabular}




\begin{tabular}{|c|c|c|c|c|}
\hline & \multicolumn{3}{|c|}{ 2439:2011 } & \multirow[b]{2}{*}{$100 \%$} \\
\hline \multirow{2}{*}{$\begin{array}{l}\text { Butir Pecah pada Agregat } \\
\text { Kasar }\end{array}$} & SMA. & \multirow{2}{*}{$\begin{array}{c}\text { SNI } \\
7619: 2012\end{array}$} & $100 / 90 *$ & \\
\hline & $\begin{array}{l}\text { Lainy } \\
\text { a. }\end{array}$ & & $95 / 90 * *)$ & - \\
\hline \multirow[t]{2}{*}{ Partikel Pipih dan Lonjong } & SMA & \multirow{2}{*}{$\begin{array}{c}\text { SNI } \\
8287: 2016 \\
\text { Perbandingan } \\
1: 5\end{array}$} & Maks. 5\% & $0 . \%$ \\
\hline & $\begin{array}{l}\text { Lainy } \\
\text { a }\end{array}$ & & $\begin{array}{c}\text { Maks. } \\
10 \%\end{array}$ & - \\
\hline \multicolumn{2}{|c|}{ Material Loloas Ayakan No.200 } & $\begin{array}{l}\text { SNI ASTM } \\
\text { C117:2012 }\end{array}$ & Maks. $1 \%$ & 0.25 \\
\hline
\end{tabular}

\section{Hasil Pengujian Karakteristik Agregat Halus}

Pemeriksaan ini dimaksudkan untuk menentukan berat jenis agregat halus dan kemampuan menyerap air serta nilai setara pasirnya. Hasil dari pengujian agregat halus dilaboratorium dapat dilihat pada tabel 3

Tabel 3. Hasil pengujian karakteristik agregat halus pada SMA (stone matrix asphalt)

\begin{tabular}{cccc}
\hline Pengujian & Metode Pegujian & Nilai & Hasil \\
& SNI 03-4428-1997 & Min. 50 \% & P5,0 \% \\
\hline $\begin{array}{c}\text { Nilai setara pasir } \\
\text { Pji Rongga Tanpa }\end{array}$ & SNI 03-6877-2002 & Min. 45 & $57,2 \%$ \\
\hline $\begin{array}{c}\text { Gempulan Lempung dan Butir - } \\
\text { butir mudah Pecah dalam Agregat }\end{array}$ & SNI 03-4141-1996 & Maks. 1\% & $0,25 \%$ \\
\hline Agregat Lolos Ayakan No. 200 & SNI ASTM C117:2012 & Maks. 10\% & $6,60 \%$ \\
\hline
\end{tabular}

\section{Analisa Saringan}

Untuk menentukan nilai gradasi campuran agregat menggunakan metode analitis. Adapun hasil nya dapat dilihat pada tabel 4.

Tabel 4. Pemeriksaan gabungan analisa saringan

\begin{tabular}{|c|c|c|c|c|c|c|c|c|}
\hline \multirow{4}{*}{$\begin{array}{c}\text { No. } \\
\text { Saringan }\end{array}$} & \multicolumn{3}{|c|}{ Gradasi Aggregate } & \multicolumn{5}{|c|}{ Gradasi Campuran Aggregate } \\
\hline & \multirow{3}{*}{$\begin{array}{l}\text { Agregat } \\
\text { Halus }\end{array}$} & \multirow{3}{*}{$\begin{array}{c}\text { Batu } \\
\text { Pecah } \\
(0,5-10 \\
\mathrm{mm})\end{array}$} & \multirow{3}{*}{$\begin{array}{c}\text { Batu } \\
\text { Pecah } \\
(10-20 \\
\text { mm) }\end{array}$} & \multirow[t]{3}{*}{ I } & \multirow[t]{3}{*}{ II } & \multirow[t]{3}{*}{ III } & \multirow{3}{*}{$\begin{array}{c}\text { Kurva } \\
\text { Ideal }\end{array}$} & Spek. \\
\hline & & & & & & & & Gradasi \\
\hline & & & & & & & & Kasar \\
\hline $1 "$ & 100 & 100 & 100 & 100 & 100 & 100 & & \\
\hline $3 / 4 "$ & 100 & 100 & 100 & 100 & 100 & 100 & 100 & 100 \\
\hline $1 / 2 "$ & 100 & 100 & 76,1 & 97,31 & 97,31 & 97,31 & 99,31 & $90 \sim 100$ \\
\hline $3 / 8 "$ & 98,17 & 93,72 & 9,01 & 71,01 & 71,02 & 71,03 & 72,89 & $50 \sim 80$ \\
\hline \# 4 & 73,63 & 21,1 & 0,38 & 31,4 & 31,47 & 31,53 & 31,82 & $20 \sim 35$ \\
\hline$\# 8$ & 74,03 & 0,79 & 0,29 & 18,64 & 18,77 & 18,89 & 18,67 & $16 \sim 24$ \\
\hline \# 16 & 49,23 & 0,25 & 0,11 & 10,54 & 10,85 & 11,16 & & \\
\hline \# 30 & 44,34 & 0,24 & 0,1 & 10,53 & 10,84 & 11,15 & & \\
\hline
\end{tabular}




\begin{tabular}{|c|c|c|c|c|c|c|c|c|}
\hline$\# 50$ & 38,84 & 0,23 & 0,1 & 10,53 & 10,84 & 11,15 & & \\
\hline \# 100 & 29,98 & 0,19 & 0,08 & 10,5 & 10,81 & 11,12 & & \\
\hline \# 200 & 22,72 & 0,13 & 0,25 & 10,44 & 10,75 & 11,05 & 10,53 & $8 \sim 11$ \\
\hline $\begin{array}{l}\text { \% Camp. } \\
\text { Agg. }\end{array}$ & \multicolumn{3}{|c|}{ Agregat Halus } & 22 & 21,5 & 21 & & \\
\hline Terhadap & \multicolumn{3}{|c|}{ Batu Pecah $(0.50-10 \mathrm{~mm})$} & 48 & 48 & 48 & & \\
\hline Berat & \multicolumn{3}{|c|}{ Batu Pecah $(10-20 \mathrm{~mm}$} & 28 & 28 & 28 & & \\
\hline Total & \multicolumn{3}{|c|}{$\begin{array}{c}\text { Bahan Pengisi (Filler) } \\
\text { Asbuton }\end{array}$} & 2 & 2,5 & 3 & & \\
\hline & \multicolumn{3}{|c|}{ Total Persentase (\%) } & 100 & 100 & 100 & & \\
\hline
\end{tabular}

Berdasarkan tabel diatas diperoleh komposisi persenan campuran abu batu sebanyak $22 \%$, medium (bpc. 0,50-10 mm) sebanyak 48\%, bpc. 10-20 mm sebanyak $28 \%$ dan bahan pengisi (filler) yang digunakan berupa asbuton sebanyak 2\%, 2,5\% dan 3\%. Persen campuran terhadap berat total agregat halus $100 \%$ diluar persen kadar aspal. Dari hasil tabel dapat digambarkan grafik pada gambar 1.

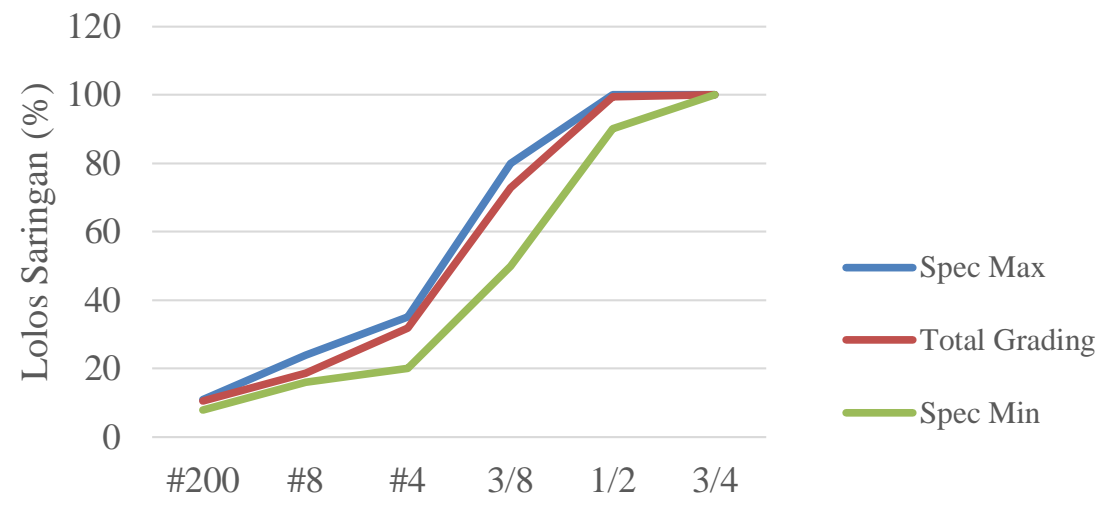

Gambar 1. Grafik hasil analisis saringan agregat kasar

\section{Hasil Pengujian Karakteristik Asbuton}

Pengujian ini untuk pemeriksaan kadar bitumen asbuton, kadar air pada asbuton, dan penetrasi asbuton. Hasil dari pengujian asbuton dilaboratorium dapat dilihat pada tabel 5 .

Tabel 5. Hasil pengujian karakteristik aspal asbuton butir tipe 5/20

\begin{tabular}{cccc}
\hline Sifat - sifat Asbuton Butir & Metode Pengujian & $\begin{array}{c}\text { Tipe } \\
5 / 20\end{array}$ & $\begin{array}{c}\text { Hasil } \\
\text { Pengujian }\end{array}$ \\
\hline Kadar bitumen asbuton; $\%$ & SNI 8279:2016 & Min.18 & $24,9 \%$ \\
\hline Ukuran butir asbuton butir & & & \\
Lolos Saringan No.3/8 $(9.5 \mathrm{~mm}) ; \%$ & & - & \\
Lolos Saringan No. 8 $(2.36 \mathrm{~mm}) ; \%$ & SNI ASTM & 100 & $100 \%$ \\
& C136:2012 & & \\
\hline
\end{tabular}




\begin{tabular}{|c|c|c|c|}
\hline Kadar air, \% & SNI 1964:2008 & Maks. 2 & $0,17 \%$ \\
\hline Penetrasi aspal asbuton pada $25^{\circ} \mathrm{C} 100$ & SNI 2456:2011 & $2-15$ & $2,42 \mathrm{~mm}$ \\
\hline $\mathrm{g}, \quad 5$ detik; $0,1 \mathrm{~mm}$ & & & \\
\hline
\end{tabular}

\section{Hasil Modifikasi}

Pada pengujian marshall dilakukan variasi filler asbuton, dimana berat agregat untuk setiap sampel dibuat 1200 gram. Pada aspal campuran normal dibuat 3 sampel benda uji. Adapun langkah-langkah perhitungan pengujian marshall untuk SMA (stone matrix asphalt) dapat dilihat pada tabel 6 .

Tabel 6. Hasil pengujian kadar aspal optimum $+2.0 \%$ asbuton butir T.5/20 untuk campuran SMA

\begin{tabular}{|c|c|c|c|c|c|c|c|c|c|c|c|c|c|c|c|c|}
\hline \multirow{4}{*}{ No. } & \multirow{3}{*}{$\frac{g_{\text {ggregat }}}{(\%)}$} & \multirow{3}{*}{$\frac{\text { A.Cmixes }}{(\%)}$} & \multicolumn{3}{|c|}{ Weight (gram) } & \multirow{3}{*}{$\begin{array}{c}\text { Volume } \\
\mathrm{Cc}\end{array}$} & \multicolumn{2}{|c|}{ Unit Weight (grm/cc) } & \multirow{3}{*}{$\frac{\text { VMA }}{(\%)}$} & \multirow{3}{*}{\begin{tabular}{l|}
$\mathrm{VIM}$ \\
$(\%)$
\end{tabular}} & \multirow{3}{*}{\begin{tabular}{|l|} 
VFA \\
$(\%)$ \\
\end{tabular}} & \multirow{3}{*}{\begin{tabular}{|c|} 
Read \\
Dial \\
stability \\
\end{tabular}} & \multicolumn{2}{|c|}{ Stability } & \multirow{2}{*}{$\frac{\text { Flow }}{\text { ion }}$} & \multirow{3}{*}{$\begin{array}{l}\text { Marshall } \\
\text { Quotient } \\
\mathrm{Kg} / \mathrm{mm}\end{array}$} \\
\hline & & & \multirow{2}{*}{ Dry } & \multirow{2}{*}{ SSD } & \multirow{2}{*}{ In Water } & & \multirow{2}{*}{ Actual } & \multirow{2}{*}{$(\%)$} & & & & & Calibrasi & Correlation & & \\
\hline & & & & & & & & & & & & & $\mathrm{Kg}$ & $\mathrm{Kg}$ & $\mathrm{mm}$ & \\
\hline & a & b & $\mathrm{C}$ & d & e & $f=d-e$ & $g=c / f$ & $\mathrm{k}$ & I & $\mathrm{J}$ & $\mathrm{k}$ & $\mathrm{L}$ & $\mathrm{m}$ & $\mathrm{n}=\mathrm{m} * \mathrm{scr}$ & 0 & $\mathrm{p}=\mathrm{n} / \mathrm{0}$ \\
\hline & & & & & & & & & & & & & & & & \\
\hline 1 & 94,75 & 5,75 & 1191,9 & 1198,3 & 681,5 & 516,8 & 2.306 & & & & & 76 & 1533 & 1533 & 3,20 & \\
\hline 2 & 94,75 & 5,75 & 1188,1 & 1194,7 & 680,5 & 514,2 & 2.311 & & & & & 68 & 1372 & 1372 & 3,40 & \\
\hline 3 & 94,75 & 5,75 & 1192,0 & 1200,1 & 682,7 & 517,4 & 2.304 & & & & & 68 & 1372 & 1372 & 3,00 & \\
\hline \multicolumn{2}{|c|}{ Average } & & & & & & 2.307 & 2.416 & 15,77 & 4,52 & & & & 1425 & 3,20 & \\
\hline Bj.bulk & 2595 & Bj.Bitument & 1.030 & $\mathrm{Gmm}$ & 2.433 & Bj.Eff Agg & 2.630 & Absp Bitumen & & 0,530 & 71,37 & & & & & \\
\hline
\end{tabular}

Tabel 7. Hasil pengujian kadar aspal optimum $+2.5 \%$ asbuton butir T.5/20 untuk campuran

SMA

\begin{tabular}{|c|c|c|c|c|c|c|c|c|c|c|c|c|c|c|c|c|}
\hline \multirow{4}{*}{ No. } & \multirow{3}{*}{$\begin{array}{c}\text { Aggregate } \\
(\%)\end{array}$} & \multirow{3}{*}{\begin{tabular}{|c|} 
A.C mixes \\
$(\%)$
\end{tabular}} & \multicolumn{3}{|c|}{ Weight (gram) } & \multirow{3}{*}{$\begin{array}{c}\text { Volume } \\
\mathrm{Cc}\end{array}$} & \multicolumn{2}{|c|}{ Unit Weight ( grm/cc) } & \multirow{3}{*}{$\begin{array}{c}\text { VMA } \\
(\%)\end{array}$} & \multirow{3}{*}{$\frac{\mathrm{VIM}}{(\%)}$} & \multirow{3}{*}{$\frac{\text { VFA }}{(\%)}$} & \multirow{3}{*}{$\begin{array}{c}\text { Read } \\
\text { Dial } \\
\text { stability } \\
\end{array}$} & \multicolumn{2}{|c|}{ Stability } & \multirow{2}{*}{$\frac{\text { Flow }}{\text { tion }}$} & \multirow{3}{*}{\begin{tabular}{|l|} 
Marshall \\
Quotient \\
$\mathrm{Kg} / \mathrm{mm}$ \\
\end{tabular}} \\
\hline & & & \multirow{2}{*}{ Dry } & \multirow{2}{*}{ SSD } & \multirow{2}{*}{ In Water } & & \multirow{2}{*}{ Actual } & \multirow{2}{*}{$(\%)$} & & & & & \multirow{2}{*}{\begin{tabular}{|c|} 
Calibrasi \\
$\mathrm{Kg}$ \\
\end{tabular}} & Correlation & & \\
\hline & & & & & & & & & & & & & & $\mathrm{Kg}$ & $\mathrm{mm}$ & \\
\hline & $\mathrm{a}$ & b & $\mathrm{C}$ & d & $\mathrm{e}$ & $f=d-e$ & $g=c / f$ & $\mathrm{k}$ & I & $\mathrm{J}$ & $\mathrm{k}$ & $\mathrm{L}$ & $\mathrm{m}$ & $\mathrm{n}=\mathrm{m}^{*} \mathrm{ser}$ & 0 & $p=n / 0$ \\
\hline & & & & & & & & & & & & & & & & \\
\hline 1 & 94,75 & 5,75 & 1196,7 & 1203,1 & 682,8 & 520,3 & 2.300 & & & & & 76 & 1533 & 1533 & 4 & \\
\hline 2 & 94,75 & 5,75 & 1195,2 & 1199,8 & 680,8 & 519 & 2.303 & & & & & 75 & 1513 & 1513 & 4 & \\
\hline 3 & 94,75 & 5,75 & 1184,5 & 1192,6 & 678,1 & 514,5 & 2.302 & & & & & 77 & 1553 & 1553 & 2,5 & \\
\hline \multicolumn{2}{|c|}{ Average } & & & & & & 2.302 & 2.416 & 15,96 & 4,73 & & & & 1533 & 3,5 & 438 \\
\hline j.boulk & 2.595 & Bj.Bitument & 1.030 & $\mathrm{Gmm}$ & 2.433 & Bj.Eff Agg & 2.630 & Absp Bitumen & & 0,530 & 70,36 & & & & & \\
\hline
\end{tabular}

Tabel 8. Hasil pengujian kadar aspal optimum $+3.0 \%$ asbuton butir T.5/20 untuk campuran

SMA

\begin{tabular}{|c|c|c|c|c|c|c|c|c|c|c|c|c|c|c|c|c|}
\hline \multirow{4}{*}{ №. } & \multirow{3}{*}{\begin{tabular}{|c|} 
Aggregate \\
$(\%)$
\end{tabular}} & \multirow{3}{*}{\begin{tabular}{|c|} 
A.C mixes \\
$(\%)$
\end{tabular}} & \multicolumn{3}{|c|}{ Weight (gram) } & \multirow{3}{*}{\begin{tabular}{|c|c|} 
Volume & \\
$\mathrm{cc}$ & \\
\end{tabular}} & \multicolumn{2}{|c|}{ Unit Weight $(\mathrm{grm} / \mathrm{cc})$} & \multirow{3}{*}{ VMA } & \multirow{3}{*}{$\frac{\mathrm{VIM}}{(\%)}$} & \multirow{3}{*}{$\frac{\mathrm{VFA}}{(\%)}$} & \multirow{3}{*}{$\begin{array}{c}\text { Read } \\
\text { Dial } \\
\text { stability }\end{array}$} & \multicolumn{2}{|c|}{ Stability } & \multirow{2}{*}{$\begin{array}{l}\text { Flow } \\
\text { ion }\end{array}$} & \multirow{2}{*}{$\begin{array}{l}\text { Marshall } \\
\text { Quotient }\end{array}$} \\
\hline & & & \multirow{2}{*}{ Dry } & \multirow{2}{*}{ SSD } & \multirow{2}{*}{ In Wate } & & \multirow{2}{*}{ Actual } & \multirow{2}{*}{$\begin{array}{|cc|}\text { AАSTHO } & \text { T } \\
209-74 & \\
\end{array}$} & & & & & Calibrasi & Correlation & & \\
\hline & & & & & & & & & & & & & $\mathrm{Kg}$ & \begin{tabular}{l|l}
$\mathrm{Kg}$ \\
\end{tabular} & $\mathrm{mm}$ & $\mathrm{Kg} / \mathrm{mm}$ \\
\hline & A & $\mathrm{b}$ & c & d & $\mathrm{e}$ & $f=d-e$ & $g=c / f$ & & $\mathrm{I}$ & $\mathrm{J}$ & $\mathrm{k}$ & $\mathrm{L}$ & $\mathrm{m}$ & $\mathrm{n}=\mathrm{m}^{*} \mathrm{ser}$ & 0 & $\mathrm{p}=\mathrm{n} / 0$ \\
\hline & & & & & & & & & & & & & & & & \\
\hline 1 & 94,75 & 5,75 & 1188,6 & 1193,5 & 678,0 & 515,5 & 2.306 & & & & & 88 & 1775 & 1775 & 3,40 & \\
\hline 2 & 94,75 & 5,75 & 1184,0 & 1188,9 & 676,2 & 512,7 & 2.309 & & & & & 76 & 1533 & 1533 & 2,30 & \\
\hline 3 & 94,75 & 5,75 & 1196,9 & 1201,8 & 680,4 & 521,4 & 2.296 & & & & & 88 & 1775 & 1775 & 2,50 & \\
\hline Average & & & & & & & 2.304 & 2.389 & 15,90 & 3,57 & 77,55 & & & 1694 & 2,73 & 620 \\
\hline Bj.bulk & 2.595 & Bj.Bitument & 1.030 & $\mathrm{Gmm}$ & 2.433 & Bj.Eff Agg & 2.630 & Absp Bitument & & 0,530 & & & & & & \\
\hline
\end{tabular}




\section{Pembahasan}

Pengujian Marshall untuk aspal SMA (Stone Matrix Asphalt) pada campuran filler asbuton T.5/20 dengan kadar aspal 4,5\%, 5\%,5,5\%, dan 6,0\% diperoleh nilai kadar aspal optimum sebesar 5,75\%. Setelah didapatkan kadar aspal optimum dilakukan modifikasi dengan penambahan asbuton berbutir T.5/20 pada campuran aspal sebanyak 2\%, 2,5\%, dan 3\%.

Nilai stabilitas pada penambahan Asbuton Berbutir T.5/20 untuk 2\% sebesar $1425 \mathrm{~kg}$, penambahan 2,5\% sebesar $1533 \mathrm{~kg}$, dan penambahan 3\% sebesar $1694 \mathrm{~kg}$. Nilai stabilitas yang diperoleh memenuhi Spesifikasi Umum Bina Marga 2018 Revisi 2 yaitu besar dari $750 \mathrm{~kg}$. Stabilitas merupakan indikator kekuatan lapis perkerasan dalam memikul beban lalu-lintas.

Nilai Void In Total Mix (VIM) pada penambahan Asbuton Berbutir T.5/20 untuk 2\% sebesar $4,52 \%$, penambahan $2,5 \%$ sebesar $4,73 \%$, dan penambahan $3 \%$ sebesar $3,57 \%$. Semakin tinggi nilai VIM menunjukan semakin besar rongga dalam campuran.

Nilai VIM yang didapatkan nilainya semakin besar dan memenuhi Spesifikasi Umum Bina Marga 2018 Revisi 2. Perencanaan aspal SMA(Stone Matrix Asphalt) didesain untuk mendapatkan kadar rongga yang besar. Nilai Void in Mineral Agregat (VMA) pada penambahan Asbuton Berbutir T.5/20 untuk penambahan 2\% sebesar 15,77\%, penambahan $2,5 \%$ sebesar $15,96 \%$, dan penambahan $3 \%$ sebesar $15,90 \%$ Nilai VMA yang didapatkan semakin kecil nilainya sehingga tidak memenuhi Spesifikasi Umum Bina Marga 2018 Revisi 2. VMA digunakan sebagai ruang untuk menampung aspal dan volume rongga udara yang dipergunakan dalam campuran SMA(Stone Matrix Asphalt). Perencanaan aspal SMA(Stone Matrix Asphalt) didesain untuk mendapatkan kadar rongga yang besar. Nilai Void Filled With Asphalt (VFA) pada penambahan Asbuton Berbutir T.5/20 untuk 2\% sebesar 71,37\%, penambahan $2,5 \%$ sebesar $70,36 \%$, dan penambahan $3 \%$ sebesar $77,55 \%$. Pada nilai VFA tidak memiliki batas minimal dan maksimal pada Spesifikasi Umum Bina Marga 2018 Revisi 2. Nilai flow atau kelelehan pada penambahan Asbuton Berbutir T.5/20 untuk penambahan 2\% sebesar $3,20 \mathrm{~mm}$, penambahan $2,5 \%$ sebesar $3,50 \mathrm{~mm}$, dan penambahan $3 \%$ sebesar $2,73 \mathrm{~mm}$. Nilai flow yang didapatkan memenuhi syarat Spesifikasi Umum Bina Marga 2018 Revisi 2. Nilai flow merupakan nilai batas kekuatan stabilitas dari benda uji yang telah mengalami kehancuran antara komponen material pada benda uji.

\section{SIMPULAN}

Pengujian Marshall pada campuran SMA (Stone Matrix Asphalt) dengan kadar aspal 4,5\%, 5\%, 5,5\% dan $6 \%$ diperoleh nilai kadar aspal optimum sebesar 5,75\%. Setelah didapatkan kadar aspal optimum dilakukan modifikasi dengan penambahan asbuton butir T.5/20 pada campuran aspal sebanyak $2 \%, 2,5 \%$, dan 3\%. Pada uji $\mathrm{T}$ diperoleh pengaruh penambahan asbuton butir T.5/20 pada karakteristik Marshall yaitu nilai VIM,VFA, dan stabilitas yang signifikan terhadap nilai karakteristik Marshall. Aspal SMA (Stone Matrix Asphalt) didesain untuk mendapatkan kadar rongga yang besar dan pada penambahan asbuton butir T.5/20 nilai VIM yang diperoleh sesuai yang direncanakan, sedangkan nilai VMA yang didapatkan nilainya tidak masuk Spesifikasi Umum Bina Marga 2018 Revisi 2

\section{UCAPAN TERIMA KASIH}

Terima kepada Laboratorium PT. RMB (Riau Mas Bersaudara) yang telah banyak membantu didalam pengerjaan penelitian ini.

\section{DAFTAR PUSTAKA}

Apriawan, A. T. 2010, Analisis Karakteristik Marshall Pada Aspal Beton Campuran

Panas Dengan Bahan Tambah Asbuton Butir, Tugas Akhir, universitas negri surakarta, Surakarta. 
Harlan, J. 2018. Analisis Regresi Linear. Gunadarma, Depok

Mamari, R. L., 2017 . Studi Perencanaan Perkerasan Lentur Jalan Raya Dengan Standar Bina Marga Pada Ruas Jalan Sentani-Warumbain Km 41+000-Km 61+000 (20 Km), Tugas Akhir, Institut Teknologi Nasional, Malang.

Raharjo, N. E., 2008, Pengaruh Penggunaan Aspal Buton Sebagai Filler Campuran Split Mastic Asphalt Terhadap Karakteristik Marshall, Jurnal Pendidikan Teknologi dan Kejuruan, Vol.17 No.1, pp.39-60, ISSN : 2477-2410.

Ramdhani, F., 2015, Kadar Optimum Filler Asbuton Butir T.5/20 Dalam Campuran Perkerasan Asphalt Concrete-Wearing Course (AC-WC). Jurnal Kajian Teknik Sipil, Vol.3 No.1, pp.32-38, ISSN : 0854-4735.

Suaryana, N., 2016, Pengembangan Model Deformasi Permanen Untuk Campuran Stone Matrix Asphalt, Jurnal Jalan Jembatan, Vol.34 No.2, pp.66-81 ISSN : 19070284 .

Timbonga, C. F., 2021, Pemanfaatan Batu Gunung Limbong Kecamatan Rantepao Dalam Campuran Stone Matrix Asphalt Kasar, Jurnal Teknik Sipil UKI-Paulus Makassar, Vol.3 No.1, pp.31-39, ISSN : 2775-8613. 